Graphical Abstract

Synthesis, crystal structure, catalytic dimerization and S-H insertion of new porphyrin diazoketones

Daniel Carriéa ${ }^{a}$ Thierry Roisnel ${ }^{\mathrm{a}}$ and Gérard Simonneaux ${ }^{\mathrm{a}, *}$

${ }^{a}$ Univ Rennes, CNRS, ISCR-UMR 6226, F-35000 Rennes, France

e-mail address : gerard.simonneaux@univ-rennes1.fr

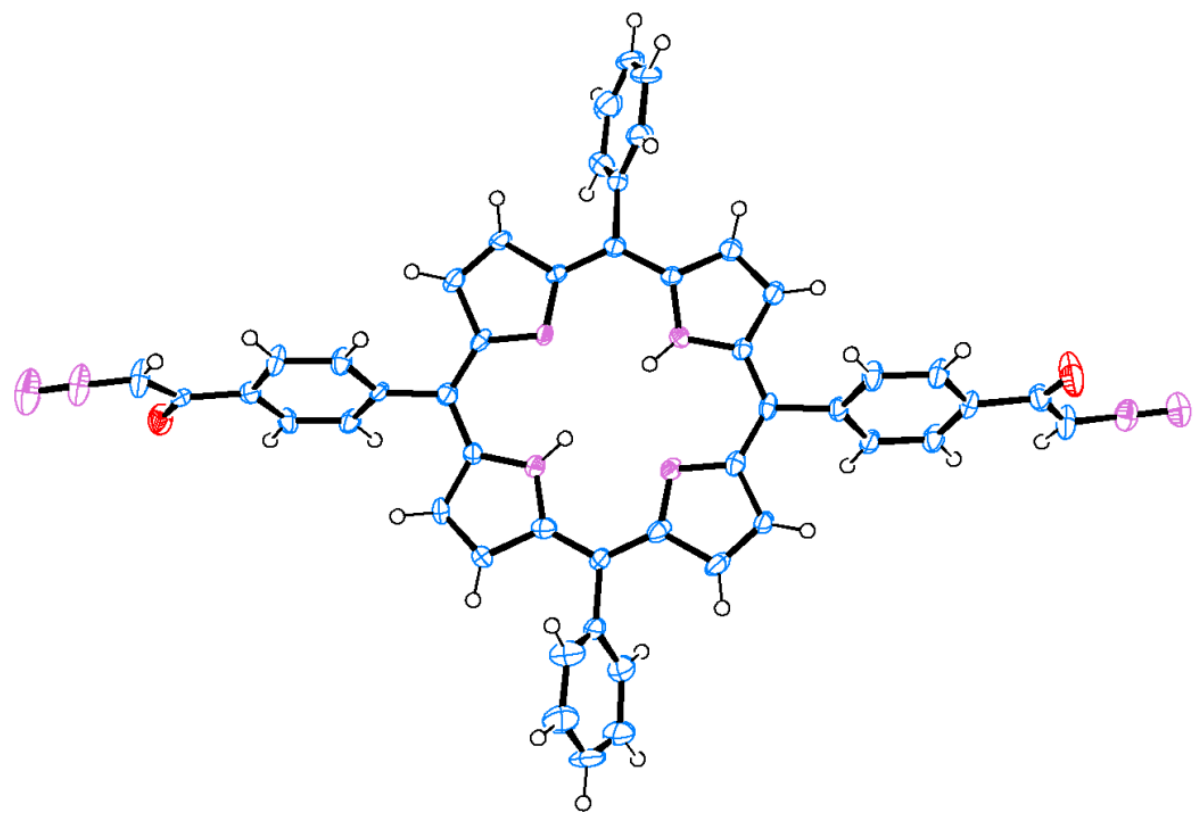




\title{
Synthesis, crystal structure, catalytic dimerization and S-H insertion of new porphyrin diazoketones
}

\author{
Daniel Carriéa $^{\text {a Thierry Roisnel }}{ }^{\mathrm{a}}$ and Gérard Simonneaux ${ }^{\mathrm{a}, *}$ \\ ${ }^{a}$ Univ Rennes, CNRS, ISCR-UMR 6226, F-35000 Rennes, France \\ e-mail address : gerard.simonneaux@univ-rennes1.fr
}

\begin{abstract}
Porphyrin diazoketones were synthesized from the corresponding porphyrin acetyl chloride by treatment with trimethylsilyldiazomethane in $60-80 \%$ yield. The solid-state structure of one of the two bis-diazo derivatives (trans isomer) was determined by single-crystal X-ray diffraction analysis. Thiol insertion and cis-selectivity in the coupling reactions of porphyrin diazoketones catalyzed by ruthenium porphyrin were observed.
\end{abstract}

Keywords : porphyrin diazoketones ; X-ray molecular structure ; dimerization ;

S-H insertion

\section{Introduction}

Among various functional groups, diazo derivatives are particularly attractive due to their high reactivities. Thus $\alpha$-diazoketones are of large interest due to their application in organic synthesis because these are intermediates in a range of chemical transformations, including dipolar cycloaddition, cyclopropanations and the homologation of carboxylic acid known as the Arndt-Eistert reaction [1].

Owing to the fruitful development of the synthesis of porphyrins, porphyrin chemists have gained a variety of potent tools to create various types of porphyrin-based materials that are difficult to prepare through conventional organic chemistry [2]. Functionalization reactions of meso-tetra-aryl-substituted porphyrins have been largely developed for the preparation of many porphyrin molecules which are essential for photodynamic therapy, bioimaging probes, molecular wires and so forth [3]. Therefore to achieve these fascinating functions, design and synthesis of structurally diverse molecules are essential. Surprisingly, simple $\alpha$-diazoketone 
substituted meso-tetraphenyl-porphyrin have not been yet prepared. As part of a program investigating porphyrin diazocarbonyl methodologies [4-8], we have studied the functionalization of tetraarylporphyrin using trimethylsilyldiazomethane as reactive intermediates. Herein we report the synthesis of several diazoketone functionalized porphyrins and their chemical reactivity.

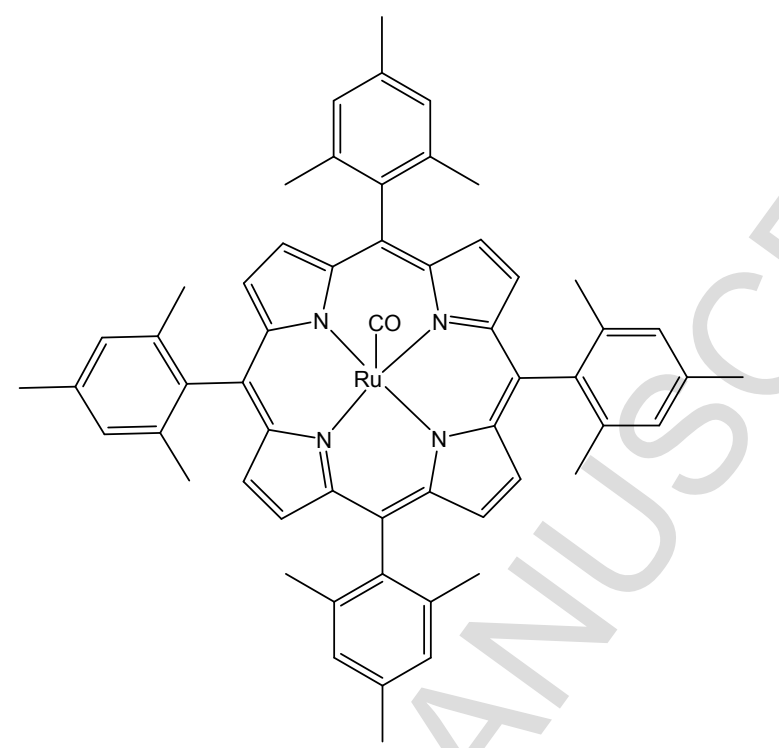

Figure 1. Tetramesitylporphyrin ruthenium carbon monoxide (TMPRuCO).

2. Experimental

\subsection{General}

All reactions were performed under argon. Solvents were distilled from an appropriate drying agent prior to use: $\mathrm{CH}_{2} \mathrm{Cl}_{2}$ from $\mathrm{CaH}_{2}$. Commercially available reagents were used without further purification unless otherwise stated. All reactions were monitored by TLC with Merck precoated aluminum foil sheets (Silica gel 60 with fluorescent indicator UV254). Compounds were visualized with UV light at $254 \mathrm{~nm}$. Column chromatographies were carried out using silica gel from Merck (0.063-0.200 mm). ${ }^{1} \mathrm{H}$ NMR and ${ }^{13} \mathrm{C}$ NMR in $\mathrm{CDCl}_{3}$ were recorded using Bruker (Advance 400dpx spectrometer) at $400 \mathrm{MHz}$ and $125 \mathrm{MHz}$, respectively. High resolution mass spectra were recorded on a Thermo-Fisher Q-Exactive (Q-Tof 2) spectrometer in ESI positif mode at the CRMPO at Rennes.

5-(4-carbomethoxyphenyl)-10,15,20-triphenylporphyrin and the corresponding acid were prepared from the method reported by Mishra [9]. Disubstituted tetraarylporphyrins were prepared as previously reported [10]. 


\subsection{Synthesis}

\subsubsection{Preparation of mono-diazo compound 1}

Hydrolysis of 5-(4-methoxycarbonylphenyl)10,15,20-triphenylporphyrin (150 mg, 0.223 mmol) was carried out with $\mathrm{NaOH}(400 \mathrm{mg}, 10 \mathrm{mmol})$ in $2 \mathrm{~mL}$ of ethanol and $10 \mathrm{~mL}$ of toluene at $70{ }^{\circ} \mathrm{C}$ for $2 \mathrm{~h}$. After evaporating the ethanol, $1 \mathrm{~N} \mathrm{HCl}$ aqueous solution was added until the $\mathrm{pH}$ was less than 5. After filtration of the precipitate, the solid was washed with water. Then the solid was dried for one night at $80^{\circ} \mathrm{C}$. The purple solid was dissolved in $2 \mathrm{~mL}$ of thionyl chloride and refluxed overnight. After removing $\mathrm{SOCl}_{2}$ under reduced pressure and drying, the acid chloride was used to react with triethylamine dissolved in $8 \mathrm{~mL}$ of tetrahydrofuran. Trimethylsilyldiazomethane ( 2 equiv) was then added at $0{ }^{\circ} \mathrm{C}$ for $1 \mathrm{~h}$. After stirring for two days at room temperature, the solution was then evaporated, dissolved in $\mathrm{CH}_{2} \mathrm{Cl}_{2}$ and purified though a silica gel column $\left(\mathrm{CH}_{2} \mathrm{Cl}_{2}\right)$. Yield 75\%. ${ }^{1} \mathrm{H}$ NMR (400 $\left.\mathrm{MHz}, \mathrm{CD}_{2} \mathrm{Cl}_{2}\right): \delta 8.92$ (s broad, $6 \mathrm{H}), 8.86$ (s broad, 2H), 8.31 (AB syst., 2H), 8.27 (m, 6H), 8.11 (AB syst., 2H), 7.97-7.65 (m, 9H), $6.24\left(\mathrm{~s}, 1 \mathrm{H}, \mathrm{CHN}_{2}\right)$ ppm. ${ }^{13} \mathrm{C} \mathrm{NMR}: \delta 185.9(\underline{\mathrm{C}}=\mathrm{O}), 146.6,142.0,136.1,134.7,134.5$, $\left.131.3,127.8,126.7,125.0,120.5,118.5,54.1 \underline{\mathrm{C} H N_{2}}\right)$ ppm. UV-vis $\left(\mathrm{CH}_{2} \mathrm{Cl}_{2}\right): \lambda_{\max / \mathrm{nm}}(\log \varepsilon)=$ 419 (5.18), 515 (3.87), 550 (3.42), 590 (3.41), 646 (3.36).Mass (ESI) (m/z): calculated for $\mathrm{C}_{46} \mathrm{H}_{31} \mathrm{~N}_{6} \mathrm{O}[\mathrm{M}+\mathrm{H}]^{+}:$683.25538, found: 683.2553 .

\subsubsection{Preparation of trans bis-diazocompound 2}

The preparation from the corresponding trans bis-diazoester derivative, is similar to the preparation of 1 , excepted that 4 equivalents of trimethylsilyldiazomethane were used. ${ }^{1} \mathrm{H}$ NMR (400 MHz, $\left.\mathrm{CD}_{2} \mathrm{Cl}_{2}\right): \delta$ 9.01-8.82 (m, 8H, $\beta$ pyrrole ), 8.39-9.30 (m, 4H),8.30-8.21 (m, 4H, CH), 8.21-8.14 (m, 4H, CH), 7.93-7.72 (m, 6H), 6.25(s, 2H, $\mathrm{CHN}_{2}$ ), -2.79 (s (broad), 2H, NH).UVvis $\left(\mathrm{CH}_{2} \mathrm{Cl}_{2}\right): \lambda_{\max / \mathrm{nm}}(\log \varepsilon)=420$ (5.07), 515 (3.75), 550 (3.37), 591 (3.15), 6.46 (3.02). Mass (ESI) (m/z): calculated for $\mathrm{C}_{48} \mathrm{H}_{31} \mathrm{~N}_{8} \mathrm{O}_{2}[\mathrm{M}+\mathrm{H}]^{+}:$751.25645, found: 751.2561. Microcrystals of 2 suitable for $\mathrm{X}$-ray structure analysis were obtained by recrystallization from $\mathrm{CH}_{2} \mathrm{Cl}_{2}$ /pentane (1:1).

\subsubsection{Preparation of cis bis-diazo compound 3}

The preparation, from the corresponding cis bis-diazoester derivative, is similar to the preparation of 1 , excepted that 4 equivalents of trimethylsilyldiazomethane were used. ${ }^{1} \mathrm{H}$ NMR $\left(400 \mathrm{MHz}, \mathrm{CD}_{2} \mathrm{Cl}_{2}\right): \delta 9.10$ - $8.75(\mathrm{~m}, 8 \mathrm{H}, \beta$ pyrrole), $8.36-8.34(\mathrm{~m}, 4 \mathrm{H}), 8.27$ - 8.23 (AB syst., $4 \mathrm{H}), 8.19-8.17$ (AB syst., $4 \mathrm{H}), 7.85-7.82$ ( $\mathrm{m}, 6 \mathrm{H}), 6.25$ ( $\left.\mathrm{s}, 2 \mathrm{H}, \mathrm{CHN}_{2}\right),-2.78(\mathrm{~s}, 2 \mathrm{H}$, 
NH). ${ }^{13} \mathrm{C}$ NMR (101 MHz, Methylene chloride-d $\mathrm{d}_{2}$ ) selected data: $\delta 185.93$ (CO), 134.75, 134.51, 131.33-130.91, 126.76, 125.06, 54.32 $\left(\mathrm{CHN}_{2}\right)$. UV-vis $\left(\mathrm{CH}_{2} \mathrm{Cl}_{2}\right): \lambda_{\max / \mathrm{nm}}(\log \varepsilon) 420(5.30), 515$ (4.02), 550(3.68), 591(3.47), 646(3.32). Mass (ESI) (m/z): calculated for $\mathrm{C}_{48} \mathrm{H}_{31} \mathrm{~N}_{8} \mathrm{O}_{2}[\mathrm{M}+\mathrm{H}]^{+}$: 751.25645, found: 751.2563 .

\subsubsection{Synthesis of dimer 4}

To a distilled toluene solution $(10 \mathrm{~mL})$ containing $1 \mathrm{mg}$ of TMPRuCO, $68.7 \mathrm{mg}(0.1 \mathrm{mmol})$ of 1 dissolved in $20 \mathrm{ml}$ of toluene was added under argon. The mixture was stirred for $24 \mathrm{~h}$ at room temperature. The solution was then evaporated and purified by chromatography on silica gel column $\left(\mathrm{CH}_{2} \mathrm{Cl}_{2}\right)$ to give $65.3 \mathrm{mg}$ of 4 (Yield $\left.=80 \%\right)$. ${ }^{1} \mathrm{H}$ NMR $\left(400 \mathrm{MHz}, \mathrm{CD}_{2} \mathrm{Cl}_{2}\right): \delta 9.05$ 8.83 (m, 16H, $\beta$ pyrrole), 8.52-8.42 (m, 8H), 8.30-8.15( m, 12H), 7.90-7.67 ( m, 18H), 7.62 (s, $2 \mathrm{H}, \mathrm{COCH}),-2.77$ (s (broad), $4 \mathrm{H}, \mathrm{NH})$. UV-vis $\left(\mathrm{CH}_{2} \mathrm{Cl}_{2}\right): \lambda_{\max / \mathrm{nm}}(\log \varepsilon)=420$ (5.72), 514 (4.32), 550 (3.92), 590 (3.56), 644 (3.22). Mass (ESI) (m/z): calculated for $\mathrm{C}_{92} \mathrm{H}_{61} \mathrm{~N}_{8} \mathrm{O}_{2}$ $[\mathrm{M}+\mathrm{H}]^{+}: 1309.4912$, found: 1309.4897 .

\subsubsection{Zinc insertion in 4.}

To a saturated solution of zinc diacetate $(20 \mathrm{ml}), 100 \mathrm{mg}$ of 4 was added progressively at room temperature. The mixture was stirred for $2 \mathrm{~h}$ at room temperature. After purification by chromatography on silica gel column $\left(\mathrm{CH}_{2} \mathrm{Cl}_{2}\right)$, compound $\mathbf{5}$ was obtained in quantitative yield. ${ }^{1} \mathrm{H}$ NMR (400 MHz, $\mathrm{CD}_{2} \mathrm{Cl}_{2}$ ): $\delta$ 9.05-8.92 (m, 16H, $\beta$ pyrrole), 8.52-8.40 (m, 8H), 8.30-8.15 ( $\mathrm{m}, 12 \mathrm{H}), 7.90-7.65(\mathrm{~m}, 18 \mathrm{H}), 7.56(\mathrm{~s}, 2 \mathrm{H}, \mathrm{COCH}) . \mathrm{UV}$-vis $\left(\mathrm{CH}_{2} \mathrm{Cl}_{2}\right): \lambda_{\max / \mathrm{nm}}(\log \varepsilon)=423$ (5.65), 551 (4.46), 593 (3.90). Mass (ESI) (m/z): calculated for $\mathrm{C}_{92} \mathrm{H}_{56} \mathrm{~N}_{8} \mathrm{O}_{2}{ }^{64} \mathrm{Zn}_{2} \quad\left[\mathrm{M}^{+}\right]$: 1432.31036, found: 1432.3092 .

\subsubsection{Reaction of 1 with thiophenol.}

To a distilled toluene solution $(20 \mathrm{~mL})$ containing $1 \mathrm{mg}$ of TMPRuCO and $84.7 \mathrm{mg}(0.12 \mathrm{mmol})$ of $1,100 \mu \mathrm{l}$ of PhSH was slowly added under argon. The mixture was stirred for $24 \mathrm{~h}$ at room temperature. The solution was then evaporated and purified by chromatography on silica gel column $\left(\mathrm{CH}_{2} \mathrm{Cl}_{2}\right)$ to give $72.9 \mathrm{mg}$ of $6($ Yield $=78 \%)$. $\left.{ }^{1} \mathrm{H} \mathrm{NMR}\left(400 \mathrm{MHz}, \mathrm{CD}_{2} \mathrm{Cl}_{2}\right):\right)$ : $\delta 9.05-$ 8.80 (m, 8H, $\beta$ pyrrole), 8.42-8.32 (broad s, 4H), 8.31-8.20 (m, 6H), 7.91-7.75 (m, 9H), 7.657.55 (m, 2H), 7.49-7.39 (m, 2H), 7.39-7.30 (m,1H), 4.60 (s, 2H, $\left.\underline{\mathrm{H}}_{2} \mathrm{~S}\right),-2.79$ (s, 2H, NH). UVvis $\left(\mathrm{CH}_{2} \mathrm{Cl}_{2}\right): \lambda_{\max / \mathrm{nm}}(\log \varepsilon)=417$ (5.54), 514 (4.21), 549 (3.90), 592 (3.75), 647 (3.47). Mass (ESI) (m/z): calculated for $\mathrm{C}_{52} \mathrm{H}_{37} \mathrm{~N}_{4} \mathrm{OS}[\mathrm{M}+\mathrm{H}]^{+}:$: 765.26826, found: 765.2679. 


\section{$2.3 \quad$ X-ray structure determination}

X-ray crystallographic study: $\left(\mathrm{C}_{48} \mathrm{H}_{30} \mathrm{~N}_{8} \mathrm{O}_{2}\right) ; M=750.80$. D8 VENTURE Bruker AXS diffractometer, Mo-K $\alpha$ radiation $(\lambda=0.71073 \AA), T=150 \mathrm{~K}$; Orthorhombic $P 22_{1} 22$ (I.T.\#18), $\mathrm{a}=19.1655(7), \mathrm{b}=23.7406(11), \mathrm{c}=9.4608(4) \AA, V=4304.7(3) \AA^{3} . Z=4, d=1.158$ g.cm ${ }^{-3}, \mu=0.074 \mathrm{~mm}^{-1}$. The structure was solved by dual-space algorithm using the SHELXT program,[11] and then refined with full-matrix least-square methods based on $F^{2}(S H E L X L)$.[12] The contribution of the disordered solvents to the structure factors was calculated by the PLATON SQUEEZE procedure[13] and then taken into account in the final SHELXL-2014 least-square refinement. All non-hydrogen atoms were refined with anisotropic atomic displacement parameters. $\mathrm{H}$ atoms were finally included in their calculated positions and treated as riding on their parent atom with constrained thermal parameters. A final refinement on F2 with 9847 unique intensities and 523 parameters converged at $\omega \mathrm{R}(\mathrm{F} 2)=$ $0.1704(\mathrm{R}(\mathrm{F})=0.0706)$ for 6164 observed reflections with $\mathrm{I}>2 \sigma(\mathrm{I})$ and $\omega \mathrm{R}(\mathrm{F} 2)=0.1914(\mathrm{R}(\mathrm{F})$ $=0.1150$ ) for all independent reflections. Crystallographic data for the structure in this paper have been deposited with the Cambridge Crystallographic Data Centre as supplementary publication nos. CCDC 1560098.

Table 1

Selected bond distances and bond angles of compound 2 .

Bond Distances $(\AA)$

$\begin{array}{llll}\mathrm{C} 29-\mathrm{N} 30 & 1.314(7) & \mathrm{C} 49-\mathrm{N} 50 & 1.306(8) \\ \mathrm{N} 30-\mathrm{N} 31 & 1.124(6) & \mathrm{N} 50-\mathrm{N} 51 & 1.124(7) \\ \mathrm{C} 27-\mathrm{C} 29 & 1.419(8) & \mathrm{C} 47-\mathrm{C} 49 & 1.455(8) \\ \mathrm{C} 27-\mathrm{O} 28 & 1.232(7) & \mathrm{C} 47-\mathrm{O} 48 & 1.212(6)\end{array}$

Bond Angles $\left({ }^{\circ}\right)$

$\begin{array}{llll}\text { C29-N30-N31 } \quad 177.1(6) & \text { C49-N50-N51 }\end{array}$ 


$\begin{array}{llll}\mathrm{C} 27-\mathrm{C} 29-\mathrm{N} 30 & 115.6(5) & \mathrm{C} 47-\mathrm{C} 49-\mathrm{N} 50 & 114.9(6) \\ \mathrm{C} 29-\mathrm{C} 27-\mathrm{O} 28 & 123.5(5) & \mathrm{C} 49-\mathrm{C} 47-\mathrm{O} 48 & 121.4(5) \\ \mathrm{C} 24-\mathrm{C} 27-\mathrm{O} 28 & 119.6(5) & \mathrm{C} 44-\mathrm{C} 47-\mathrm{O} 48 & 122.2(5)\end{array}$

3. Results and discussions

3.1 Synthesis
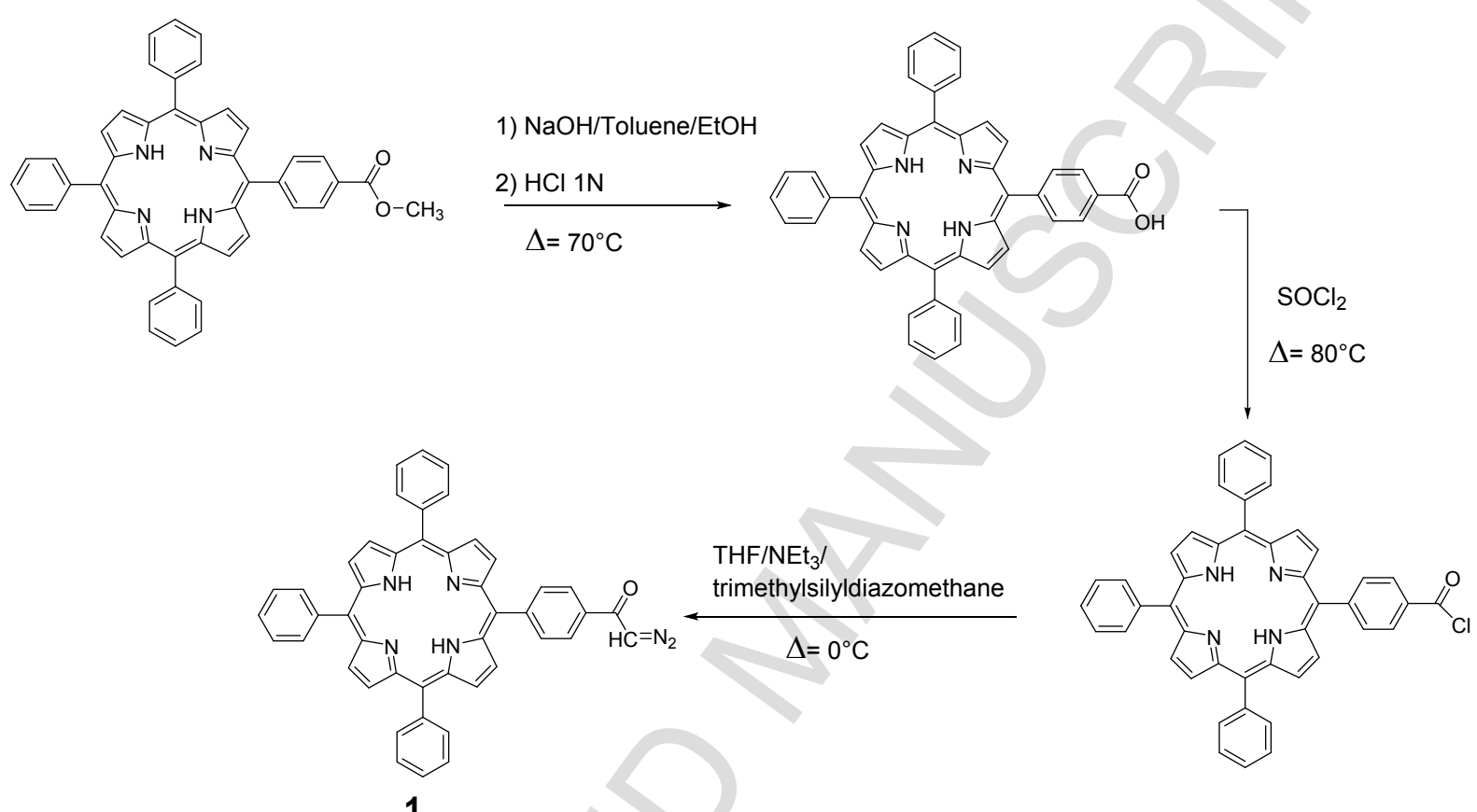

1

Scheme 1. General pathway for the synthesis of porphyrin diazoketone derivatives.

For the synthesis of porphyrin diazoketones, it was first decided to use trimethylsilyldiazomethane as a substitute of diazomethane because the latter is not only highly toxic but also explosive. Trimethylsilyldiazomethane $\left(\mathrm{TMSCHN}_{2}\right)$ has been previously used in the preparation of a variety of diazoketones from the corresponding acyl chloride by treatment with trimethylsilyldiazomethane $[1,14,15]$. Herein, we successfully adapted this recent method with porphyrin acyl chlorides that were prepared from esters. Thus, the acid was readily available from 5-(4-carbomethoxyphenyl)-10,15,20-triphenylporphyrin, from the method reported by Mishra [9]. Conversion of this acid to its acyl chloride with thionyl chloride gave a quasi-quantitative yield. The porphyrin acyl chloride was then allowed to react with 2 equivalents of $\mathrm{TMSCHN}_{2}$ in the presence of an excess of triethylamine dissolved in THF at low temperature $\left(0^{\circ} \mathrm{C}\right)$. The expected porphyrin diazoketone 1 was obtained with $75 \%$ yield after 2 days. The structural assignment of porphyrin diazoketone $\mathbf{1}$ was based on mass spectrometry 
studies and proton NMR studies. The most noticeable feature in the ${ }^{1} \mathrm{H}$ NMR spectrum was the signal corresponding to the resonances of the diazo proton $\left(\mathrm{CHN}_{2}\right)$ that appears as a singlet at $6.25 \mathrm{ppm}$. The assignment of the pyrrolic protons and corresponding carbons was achieved through 2D NMR (COSY, HMBC and HSQC) ( $\delta$ 8.4-8.6 ppm). The ${ }^{1} \mathrm{H}$ NMR spectrum also showed $\mathrm{AB}$ signals corresponding to the aromatic ring bearing the diazo group $(\delta=8.11$ and $8.31 \mathrm{ppm})$.

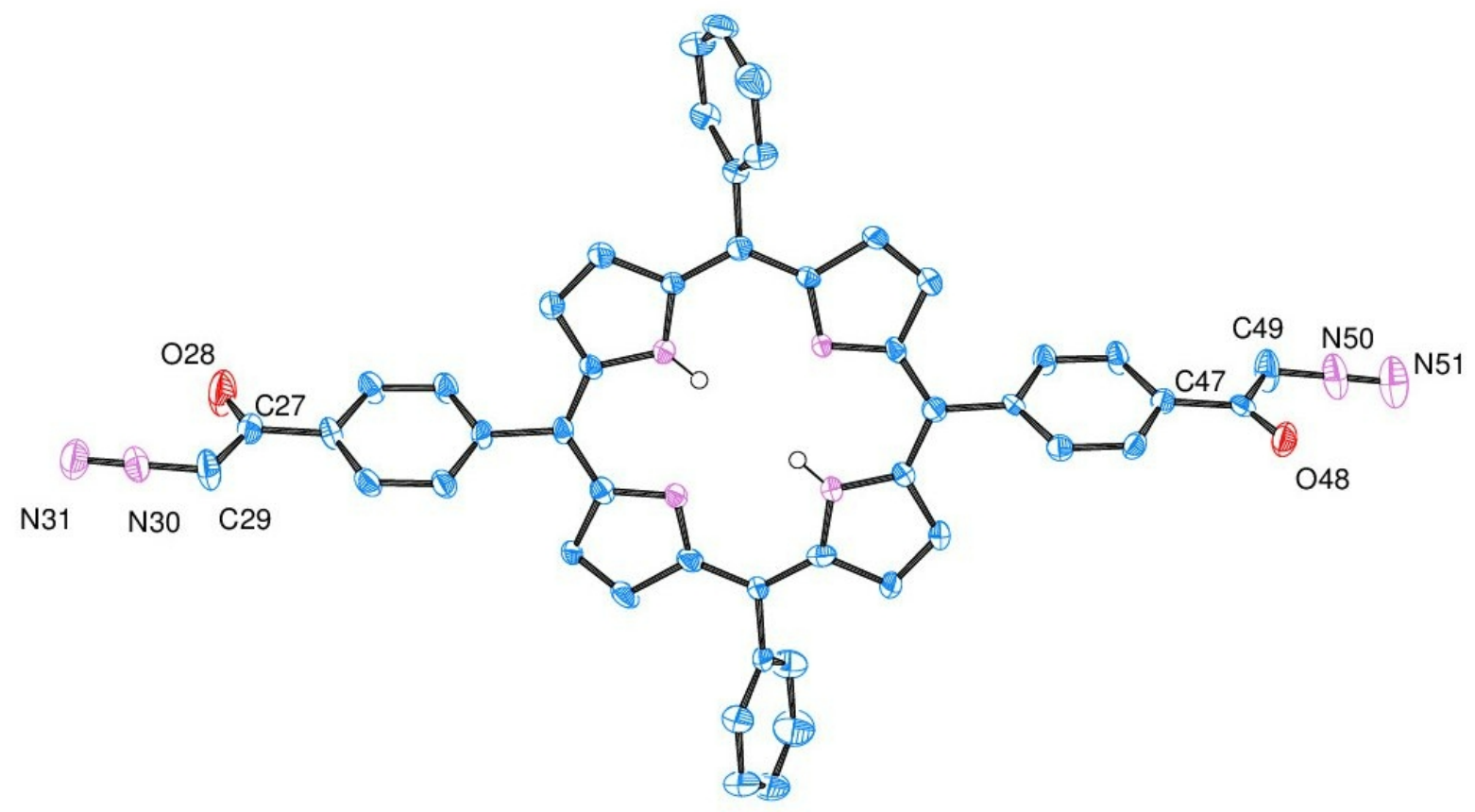

Figure 2. ORTEP structure of porphyrin diazoketone compound 2 with the atom labeling of diazo ketone groups (Hydrogen atoms removed for clarity, except $\mathrm{N}-\mathrm{H}$ of the porphyrin ring).

\subsection{Description of crystal structure}

Recently diazocarbonyl compounds have attracted much attention not only as highly useful reagents for organic synthesis but also as monomers for polymerization. Diazocarbonyl compounds can be regarded as promising monomers when they are used as a monomer for polycondensation in a form of bis(diazocarbonyl) compounds [16]. Actually, it was recently reported the first example of polycondensation of some bis(diazoketone)s with aromatic diols, where the initial objective of the examination was to utilize insertion of carbene derived from diazoketone into $\mathrm{OH}$ of the diol to obtain poly(ether ketone)s [16]. Consequently we also decided to investigate the synthesis of the trans and cis bis-diazoketones, noted $\mathbf{2}$ and $\mathbf{3}$, respectively, these two compounds being prepared from the corresponding porphyrin bis-esters. 
To better characterize the diazo group and to assure the regioselectivity, an X-ray structure determination of one of the bis-diazo isomer was undertaken (compound 2 ). The X-ray structure of monocrystals confirms the opposite situation of the two diazo groups (see Figure 2). Bisdiazoketone 2 was the first porphyrinic diazo compound to have its structure investigated by X-ray diffraction analysis. The interatomic C-N (1.311 (8) and 1.313 (8)) $\AA$ and N--N (1.124 (7) and 1.120 (7) $\AA$ )) distances for 2 (Table 1) are however quite similar to the bond length distances for 2-diazo-3oxochlorins (1.318 (4) and 1.135 (4) $\AA$ ) [17].

2
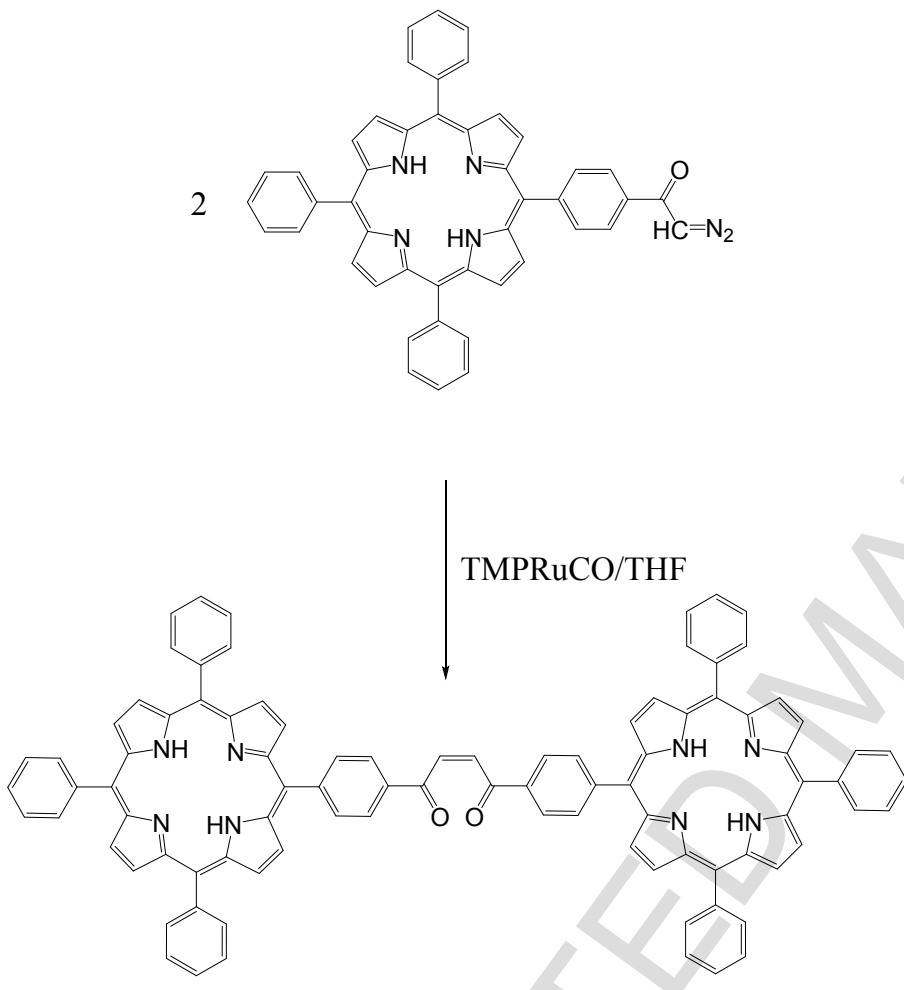

Scheme 2. Coupling reaction of porphyrin diazoketones.

\subsection{Chemical Reactivity}

Selective intermolecular coupling reactions of diazo derivatives to form cis-alkenes have been previously reported. Diazoesters and diazoketones [18-20] have been generally coupled using various catalytic systems. Metalloporphyrins have also been used to get the cis selectivity [2123]. To evaluate the reactivity of porphyrin diazoketone compound $\mathbf{1}$, its ruthenium-catalyzed homocoupling was first examined in dichloromethane (see Scheme 2) at room temperature by using tetra-mesitylporphyrin ruthenium carbon monoxide (Figure 1) as catalyst. The dimer was formed with $80 \%$ yield after $24 \mathrm{~h}$ at room temperature with complete cis stereoselectivity. The structural assignment of the porphyrin dimer $\mathbf{4}$ was based on mass spectrometry studies and 
proton NMR studies. The most noticeable feature in the ${ }^{1} \mathrm{H}$ NMR spectrum was the signal corresponding to the resonances of the olefinic proton $(\mathrm{CH}=)$ that appears as a singlet at 7.62 ppm. $\mathrm{Zn}$ metal was also inserted in the porphyrin core of $\mathbf{4}$ using a saturate solution of zinc diacetate in methanol. After $20 \mathrm{~min}$ of stirring at room temperature, the zinc porphyrin dimer $\mathbf{5}$ was obtained in a quantitative yield.

Since peptidyl diazomethyl ketones appeared to be specific inactivators of cysteine proteinases [24] insertion of diazoporphyrin ketone into S-H bonds, catalyzed by tetramesitylporphyrin ruthenium was essayed (Scheme 3). Treatment of thiophenol with diazoporphyrin 1 catalyzed by the ruthenium complex (Figure 1) gave the expected insertion of the diazo derivative into the S-H bond to get 6 in $78 \%$ yield.

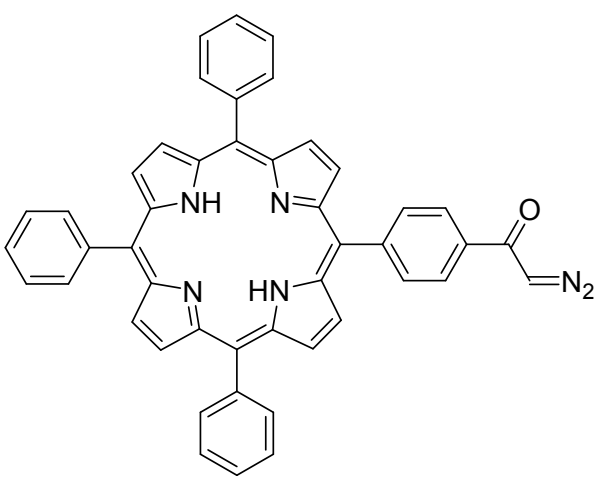

1

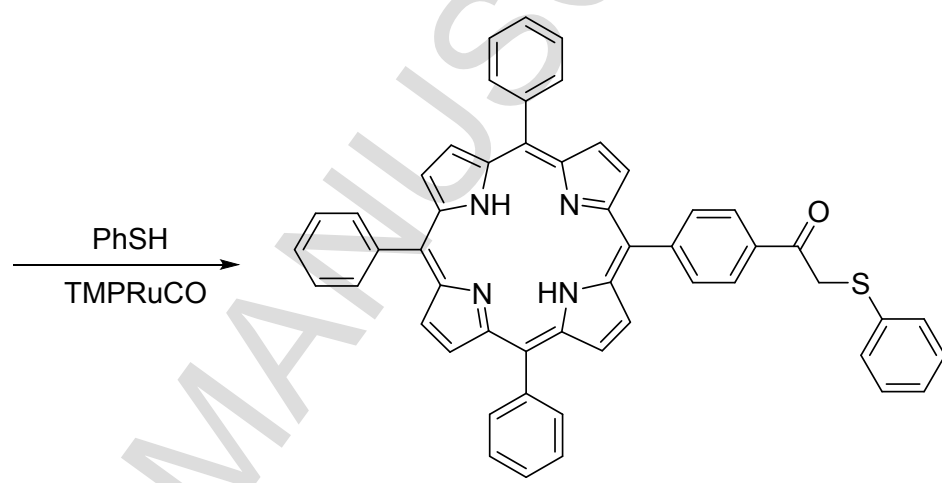

6

Scheme 3. Insertion of porphyrin diazoketone 1 into thiophenol.

\section{Conclusions}

The synthesis and reactivity of new porphyrin diazoketones occurs with good yields offering for the first time a general access to these original porphyrins. Diazo compounds in the functionalization of porphyrin macrocycles are still rare [25]. Thus the catalytic dimerization and S-H insertion were easily obtained and could offer new opportunity. An X-ray structure of a porphyrin bis-diazoketone confirms their opposite geometry. All the new derivatives were identified by NMR and mass spectral analyses (see experimental section). 
References

[1] T. Ye, M.A. McKervey, Organic synthesis with $\alpha$-diazocarbonyl compounds, Chem. Rev. 94 (1994) 1091-1160.

[2] S. Hiroto, Y. Miyake, H. Shinokubo, Synthesis and Functionalization of Porphyrins through Organometallic Methodologies, Chemical Reviews 117(4) (2017) 2910-3043.

[3] K. Kadish, K.M. Smith, R.E. Guilard, The Porphyrin Handbook (Vols. 1-10), The Porphyrin Handbook; Academic Press: Boston, MA, 2000, Vol. 1-10. (2000).

[4] E. Galardon, P. Le Maux, G. Simonneaux, Cyclopropanation of alkenes, N-H and S-H insertion of ethyl diazoacetate by Ruthenium porphyrin complexes, Tetrahedron 56 (2000) 615-621.

[5] G. Simonneaux, P. Le Maux, Optically active ruthenium porphyrins: chiral recognition and asymmetric catalysis, Coord. Chem. Rev. 228 (2002) 43-60.

[6] I. Nicolas, T. Roisnel, P. Le Maux, G. Simonneaux, Asymmetric intermolecular cyclopropanation of alkenes by diazoketones catalyzed by Halterman iron porphyrins, Tetrahedron Lett. 50 (2009) 5149-5151.

[7] P. Le Maux, I. Nicolas, S. Chevance, G. Simonneaux, Chemical reactivity of 6-diazo-5-oxo-Inorleucine (DON) catalyzed by metalloporphyrins (Fe, Ru), Tetrahedron 66(25) (2010) 4462-4468.

[8] D. Carrie, H. Srour, P. Le Maux, G. Simonneaux, Synthesis and chemical reactivity of new zinc porphyrin diazoacetates catalyzed by ruthenium and iron porphyrins, Tetrahedron Lett. 57(10) (2016) 1179-1182.

[9] B. Mishra, K.P.C. Shekar, A. Kumar, S. Phukan, S. Mitra, D. Kumar, Facile synthesis, characterization and fluorescence studies of novel porphyrin appended thiazoles, J.Heterocyclic Chem. 50 (2013) 125128.

[10] J.A. Anton, P.A. Loach, synthesis of mono,Di, and trisubstituted tetraarylporphyrins, J. Heterocyclic. Chem. 12 (1975) 573-576.

[11] G.M. Sheldrick, SHELXT - Integrated space-group and crystal-structure determination, Acta Cryst. A71 (2015) 3-8.

[12] G.M. Sheldrick, Crystal structure refinement with SHELXL, Acta Cryst. C71 (2015) 3-8.

[13] A.L. Spek, PLATON SQUEEZE: a tool for the calculation of the disordered solvent contribution to the calculated structure factors, Acta Cryst. C71 (2015) 9-18.

[14] T. Aoyama, T. Shioiri, New methods and reagents in organic synthesis. 8. Trimethylsilyldiazomethane. A new, stable, and safe reagent for the classical arndt-eistert synthesis, Tetrahedron Lett. 21(46) (1980) 4461-4462.

[15] J. Cesar, M. Sollner Dolenc, Trimethylsilyldiazomethane in the preparation of diazoketones via mixed anhydride and coupling reagent methods: a new approach to the Arndt-Eister synthesis, Tetrahedron Lett. 42 (2001) 7099-7102.

[16] E. Ihara, Y. Hara, T. Itoh, K. Inoue, Three-Component Polycondensation of Bis(diazoketone) with Dicarboxylic Acids and Cyclic Ethers: Synthesis of New Types of Poly(ester ether ketone)s, Macromolecules 44(15) (2011) 5955-5960.

[17] T. Köpke, M. Pink, J.M. Zaleski, A Facile Synthesis of 2-Diazo-3-oxochlorins by Lewis Acid Activation: Selective Modification of p-Electron Conjugated Macrocycles Synlett 14 (2006) 2183-2186.

[18] W. Baratta, A. Del Zotto, P. Rigo, cis-enediones from diazocarbonyl catalyzed by RuClC5H5PPh2, Chem. Commun. (1997) 2163-2164.

[19] A. Del Zotto, W. Baratta, G. Verardo, P. Rigo, Functionalised cis-Alkenes from the Stereoselective Decomposition of Diazo Compounds, Catalysed by [RuCl(ç5-C5H5)(PPh3)2], Eur. J. Org. Chem. (2000) 2795-2801. 
[20] D.M. Hodgson, D. Angrish, intermolecular coupling of diazoacetate using Grubbs, Chem. Eur. J. 13 (2007) 3470-3479.

[21] J.P. Collman, E. Rose, G.D. Venburg, Reactivity of Ruthenium 5,10,15,20-Tetramesitylporphyrin towards Diazoesters: Formation of olefins, J. Chem. Soc., Chem. Commun. (1993) 934-935.

[22] G.Y. Li, C.M. Che, Highly Selective Intra- and Intermolecular Coupling Reactions of Diazo Compounds to Form cis-Alkenes Using a Ruthenium Porphyrin Catalyst, Org. Lett. 6 (2004) 1621-1623. [23] L.K. Baumann, H.M. Mbuvi, G. Du, L.K. Woo, Iron Porphyrin Catalyzed NH Insertion Reactions with Ethyl Diazoacetate, Organometallics 26(16) (2007) 3995-4002.

[24] E. Shaw, Peptidyl diazomethanes as inhibitors of cysteine and serine proteinases, Methods Enzymol. 244 (1994) 649-656.

[25] A.T.P.C. Gomes, M.G.P.M.S. Neves, J.A.S. Cavaleiro, Diazo compounds in the functionalization of porphyrin macrocycles, J. Porph. Phtalocyan. 15 (2011) 835-847. 
The solid-state structure of a trans (bis-diazoketone) porphyrin was determined by crystal X-ray diffraction analysis

Cis selectivity is observed for catalytic dimerization of porphyrin diazoketones

Thiol insertion of porphyrin diazoketone is catalyzed by ruthenium porphyrin 